\title{
Food security measures in Sub-Saharan Africa. A validation of the LSMS-ISA scale*
}

\author{
Olivia Bertelli ${ }^{\dagger}$
}

\begin{abstract}
Despite the international community's emphasis on the need to achieve food security, there is still much debate surrounding its measurement, due mainly to its multidimensional aspects. This paper investigates the capacity of a new type of measure, food security scales, to capture dimensions of food security that other measures, such as food expenditures, caloric availability and food diversity, may miss. Drawing on nationally representative household panel data from Malawi, Nigeria and Tanzania, I find that the scale is a useful complementary measure to standard measures. Cross-section and panel analysis shows that the scale provides further insights into food vulnerability and coping strategies characteristic of food insecurity, dimensions not captured by the standard measures.
\end{abstract}

Keywords: Food Security, Sub-Saharan Africa, measurement.

JEL codes: I32, O13.

\section{Introduction}

The right to food is one of the basic needs stated in the Universal Declaration of Human Rights and is the central focus of the first Millennium Development Goal and the second Sustainable Development Goal. The importance of food security has made its measurement a priority as seen from the profusion of definitions and indicators, the majority of which focus on one aspect of food security at a time (see Hoddinott (2001) for an overview).

Capturing the multifaceted aspects of food security therefore often calls for the use of an array of indicators. Yet their figures are sometimes hard to reconcile, as they tend to capture different dimensions of food security. The nutritional literature has been developing a new type of measure, food security scales, over the last twenty years to combine several dimensions into one single indicator. These measures are based on a subjective self-assessment of household

*The research behind these results received funding from the European Union's Seventh Framework Programme FP7/2007-2011 under Grant Agreement n.290693 FOODSECURE. The author only is responsible for any omissions or errors. Neither the FOODSECURE project nor any of its partner organizations, nor any organization of the European Union or European Commission is accountable for the content of the paper.

${ }^{\dagger}$ University Paris Dauphine, PSL, LEDa, DIAL. Email: olivia.bertelli@dauphine.psl.eu 
food security as reported by respondents, taking into account multiple aspects of food security (Barrett, 2002).

First introduced in the United States by Radimer et al. (1990), the scales consist of a set of questions regarding specific circumstances surrounding food-related concerns, food preferences, food variety and a lack of food quantity. They cover aspects such as worrying about a lack of food, restricted food variety, borrowing food and lacking food at home. ${ }^{1}$ The scales' capacity to cover a number of food security dimensions in the same indicator makes them potentially a highly useful indicator.

Yet, their self-reported qualitative nature has called for a considerable amount of work to establish their conceptual and statistical validity (for a review see Coates (2013)). Consequently, the scales have been substantially improved over the years to reflect as closely as possible the FAO (1996) multidimensional definition of food security by identifying a set of core conditions common to the experience of food insecurity (see Cafiero et al. (2015) for an internationally valid scale). These scales have been rapidly taken up worldwide and are now used in many household surveys, in particular in Latin American countries (Coates (2004) and Melgar-Quiñonez et al. (2010)).

Nevertheless, there is a lack of sound empirical evidence on their comparative advantage over that which standard measures already capture. As a statistically valid measure, are they able to detect anything more about food security than other measures? Or are they simply another way of measuring exactly the same things? What is their contribution to the measurement of food security?

The present study investigates the added value of a food security scale measuring households food security compared to more standard measures, such as food expenditures, caloric availability and food diversity. Given the scales' statistical reliability, I am interested in whether they improve our understanding of household food security or whether they are merely an easier way to capture one dimension of welfare.

To answer these questions, I rely on a large nationally representative household panel dataset collected in three different Sub-Saharan countries. The analysis is based on the World Bank LSMS-Integrated Survey on Agriculture (LSMS-ISA) data collected twice in Malawi, Nigeria and Tanzania in 2010/2011 and 2012/13. These data contain a food security scale adapted from the World Food Programme Coping Strategy Index (Maxwell and Caldwell (2008); Kisanga et al. (2012)).

The LSMS-ISA data present two main advantages over previous studies that make the analysis of its food security scale an important contribution to the literature on food security measurement. First, a set of common questions was used in all questionnaires, enabling me to assess the correlation of the scale with the other measures in different contexts. The scale is part of a large questionnaire collecting a variety of household characteristics and food security measures against which I can compare food security scales in all three countries.

\footnotetext{
${ }^{1}$ Nevertheless, the food security scales do not yet capture all dimensions of food security. The utilization dimension is, for instance, absent from the scales to date.
} 
Second, the longitudinal nature of the data means that I can explore how far these indicators concur in their measurement of food security trends for a given population over time. This represents an innovative contribution made by this study and a useful analysis for monitoring food security over time. In addition, the use of household panel data has the methodological advantage of limiting the risk of spurious correlations, by netting out unobservable time-invariant factors at the household level and covariate shocks that may affect the correlation between standard measures and the scale.

The ability to explore the same food security scale over time and across different countries is the key feature of this paper. In fact, there are still very few scales that can be applied in different contexts and to monitor the temporal evolution of food security. ${ }^{2}$ The majority of studies to date have only assessed the internal statistical validity of national scales administered in a given country at a certain time using Item Response Theory methods. ${ }^{3}$ Yet for interventions addressing food security, having a flexible and easy-to-administer tool to monitor changes in food security over space and time (and possibly improve its measurement) is a considerable advantage.

The analysis begins with an assessment of the state of food security in the three countries based on the food security scales, food expenditures and food diversity. Caloric availability is also taken into account for Tanzania. Interestingly, the data show that the share of food insecure households differs considerably depending on the measure used. Between $65 \%$ and $67 \%$ of households are deemed to be food insecure in terms of food expenditures, while the figure drops to $56-58 \%$ when the food security scale is used.

Turning to the regression estimates, the main results show that the association between the food security scales and the other measures is positive and significant over time and within the same household. Higher food expenditures, caloric availability and food diversity are associated with higher food security as measured by the scale. Yet the magnitude of the correlation is fairly low. The cross-section results indicate that, on average, households with $10 \%$ higher food expenditures or caloric availability have a food security scale z-score that is 0.02 standard deviations higher. The correlation between the scale and food diversity is higher, with one food group on average associated with roughly 0.1 standard deviation more. The results are consistent across countries and similar once household and year fixed effects are accounted for, although the magnitudes are slightly smaller.

It is interesting to note that the non-parametric estimates, confirmed by the regression results, show that the scale correlates in a non-linear way with food expenditures and caloric availability. The correlation is much higher and stronger for the sample of households living

\footnotetext{
${ }^{2}$ Previous to this study, only three studies (Deitchler et al. (2010), Melgar-Quiñonez et al. (2010) and MelgarQuiñonez et al. (2006)) adopted adequate statistical methods to validate the same scale across countries. However, the work by Deitchler et al. (2010) and Melgar-Quiñonez et al. (2010) suffers from the main limitation of drawing on datasets collected using different sample designs and sizes, for totally different purposes and often not being nationally representative. In addition, Melgar-Quiñonez et al. (2006) compared the results of hunger scales applied in different countries, but did not conduct an analysis of the scale's cross-country validity. Gulliford et al. (2006) tested the Household Food Security Survey Measure (HFSSM) across different ethnic groups in Trinidad and Tobago.

3 A remarkable contribution is the work by Cafiero et al. (2015) who showed the statistical validity of the Food Insecurity Experience Scale (FIES) across 146 countries.
} 
with less than $\$ 1.25$ per capita per day, while it becomes lower and noisier in the upper part of the distribution. This suggests that deprived households are food insecure in all types of dimensions commonly measured by the scale and the other three measures, while less deprived households may be insecure in some but not all dimensions.

To investigate the aspects of the scale that overlap with the other three measures, I replicate the main regression analysis looking at each single scale item. Results show that the highest correlations are found with respect to the most extreme food insecurity conditions and to the psychological dimension of food insecurity. Having no food at home, going a whole day and night without eating and worrying about a lack of food are the three items that constantly report the highest correlations relative to the sample mean.

Dimensions relating to food variety, food rationing and food access appear, in turn, to be specific to the scale. The strategies that show much weaker correlations with the other measures are, for instance, changing diet by reducing food variety, rationing food by reducing the number and frequency of meals, restricting adult consumption, and relying on safety nets to borrow food. Accounting for these conditions could, therefore, considerably improve the measurement of food security, making the scale a valuable complementary indicator. The scale is capable of documenting a range of possible household behavioral responses to a lack of food quantity, quality and variety, thereby improving our understanding of food security constraints.

Lastly, I explore the scale's capacity to capture food vulnerability, a dimension of food security rarely covered by standard measures. For this, I use the Consumption Adequacy Question, a self-reported measure in the Malawian LSMS-ISA questionnaire regarding the level of food adequacy in the household over the past 30 days. The scale correlates particularly well with this measure, in particular for the dimensions of food rationing and worrying about running out of food. These results show that the scale captures the food vulnerability dimension better than the other standard measures.

All in all, the food security scale contained in the LSMS-ISA questionnaires appears to correlate mostly with dimensions pertaining to chronic food insecurity and worrying about a lack of food. The scale appears to capture other dimensions of food security, such as food variety, food rationing, food access and food vulnerability, which makes it a valuable complementary measure of food security. These conditions, in effect, provide additional household food security information not captured by food expenditures and caloric availability.

The analysis is organized as follows. The first section reviews the food security definitions and measures. The second section describes in detail the variables of interest and provides some descriptive statistics. The third section illustrates the methodology used. The fourth section presents the main results together with the heterogeneity analysis. The last section draws the main conclusions. 


\section{Food security definitions and measures}

Measurement efforts have historically focused mainly on food availability as an important policy issue, since national governments were long deemed to play a key role in supplying food to their populations. This long placed the emphasis on the amount of food available in a country and the supply-side of food security (United Nations, 1975).

Following Sen's work on famines in the 1980s (Sen, 1981), however, the relevance of individual's food entitlement in terms of access, rather than just availability, gained momentum. In his seminal study, Sen argues that starvation can occur irrespective of a decline in food availability and that famines are, actually, caused by a failure of entitlement. Available food might not be automatically accessible, highlighting the importance of measuring food accessibility rather than just availability.

By the mid-1990s, the definition of food security also included the quality of food, nutritional components and taste preferences, giving rise to the FAO's widely accepted definition of food security (FAO, 1996):

"Food security exists when all people, at all times, have physical and economic access to sufficient, safe and nutritious food to meet their dietary needs and food preferences for an active and healthy life."

This definition encompasses the four main food security dimensions: availability, accessibility, utilization and stability (FAO (1996), FAO et al. (2013)). There as been much debate, in particular in the nutritional literature, as to whether all these aspects can really be combined into one measure of food security. Still today, food security is often measured by looking at just one single dimension at a time. For example, food supply interventions usually address exclusively food availability, even though ignoring food accessibility could fail to effectively reduce food insecurity.

Yet measuring food accessibility is no straightforward matter. It is often expressed in terms of prevalence of undernourishment, which is a measure widely criticised for being based on strong assumptions about the universality of given energy requirements, which may well, in turn, differ from country to country and even person to person (Sen, 1981). ${ }^{4}$ Food expenditures form another common food access indicator, typically collected in household surveys and often used more broadly as a proxy for wealth status. In an effort to capture food quality in addition to quantity, an indicator of food diversity, measured by the number of food groups consumed, has become common in the literature, as it has been found to be associated with child anthropometric status, food expenditures and per capita caloric availability (Hoddinott and Yohannes (2002) and Ruel (2002)). Lastly, the measures most often adopted for detecting food utilization tend to be anthropometric measures and the prevalence of underweight children under five. However,

\footnotetext{
${ }^{4}$ The prevalence of undernourishment is measured by the probability that a randomly selected individual from the reference population will be found to consume less than his/her calorie requirement for an active and healthy life (FAO et al., 2015).
} 
their collection calls for a relatively sophisticated level of expertise, making them costly and subject to measurement error.

Recent studies in the literature on food security measurement have been shifting toward considering coping strategies, which capture the psychological and social acceptability aspects of food security (Barrett, 2002). Food insecure households are identified based on the type of strategies put in place in response to a food shortage and/or lack of food variety. Among those new measures, the food security scales form an innovative tool first introduced by Radimer et al. (1990) in the United States. These scales are based on a list of questions, each focusing on a specific condition associated with being worried about running out of food and insufficient food quantity and variety, to measure respondents' food security based on the total number of positive answers to the list of questions. This makes them a simple, timely and less costly tool than food expenditures, caloric availability or anthropometric measures. Moreover, their flexibility is such that their content can be adjusted to context-specific needs.

A positive aspect associated with their ease of administration is the quality of the data collected, often better than standard measures, such as prevalence of undernourishment and food availability. These are usually based on fairly poor quality data, from developing countries in particular, such as food balance sheets on which the FAO has traditionally relied for want of suitable household surveys (FAO et al., 2015).

This feature is probably behind the widespread adoption of the food security scales today. Nowdays, they form an integral part of nationally representative surveys administered in a number of different countries and have been widely used by international organizations and national governments in recent years. In the United States the U.S. Household Food Security Survey Module (US HFSSM) has been administered annually since 1995 and has served as the model for the Latin-American scale (ELCSA) (Pérez-Escamilla et al. (2007), Melgar-Quiñonez et al. (2010), Pérez-Escamilla et al. (2011) and Comité Cientifico de la ELCSA (2012)). ${ }^{5}$ One of the most well-known examples is probably the Household Food Insecurity Access Scale (HHIAS) developed by the Food and Nutritional Technical and Assistance Project (FANTA), supported by USAID and subject of an extensive adaptation process to different contexts (see among others Frongillo et al. (2003), Food and Nutritional Technical Assistance project (2004), Fiszbein and Giovagnoli (2004), Alvarez et al. (2006), Coates et al. (2006a), Coates et al. (2006b), Coates et al. (2007), Bezuneh et al. (2008), Hackett et al. (2008), FAO (2008)). Initially proposed as a measure for use in cross-country comparisons (Coates et al., 2007), the scale's cross-country validity has, nevertheless, recently been disputed (Deitchler et al., 2010).

More recently, the Food Insecurity Experience Scale (FIES), an internationally comparable food security scale, was included in the World Gallup survey of 146 countries (Ballard et al. (2013) and Cafiero et al. (2015)). ${ }^{6}$ The FIES is designed as a global standard to which every single Gallup survey scale can be compared, to estimate comparable cross-country prevalence

\footnotetext{
${ }^{5}$ One of the first examples is the Escala Brasilerira de Inseguranca Alimentar (EBIA), in use since 2004. The Escala Latinoamericana y Caribeña de Seguridad Alimentaria (ELCSA) has been in use througout the whole Latin-American continent for a number of years now.

${ }^{6}$ This study differs from Cafiero et al. (2015) in terms of the type of data used, as I use a broad-based household panel data whereas their work is based on a cross-section of opinion polls.
} 
rates. It has now been adopted as an indicator for monitoring progress toward the Sustainable Development Goal 2.1 of ending hunger and ensuring access to food by all people by 2030 (FAO et al., 2017).

\section{Data and descriptive statistics}

The present analysis is based on the Living Standards Measurement Survey - Integrated Surveys on Agriculture (LSMS-ISA) designed by the World Bank together with national statistical offices and collected in Malawi, Nigeria and Tanzania. ${ }^{7}$

In each country, a sample of households representative at the national and urban-rural levels is selected and interviewed over multiple rounds, typically with a one or two year interval between two rounds. Tanzania was the first country to administer the LSMS-ISA survey to 3,265 households in 2008/09. These were then followed-up in 2010/11, 2012/13 and 2014/15. The first round of data collection in Malawi and Nigeria took place in 2010/11 and targeted 3,247 and 5,000 households, respectively. In Malawi two more data collection rounds followed in 2013 and 2016/17 (data not yet available). In Nigeria households were interviewed at fairly short time intervals in 2010, before and after the harvest, with around a six month interval. So each household was interviewed twice in each round of data collection. This same approach was taken for the following rounds in 2012/13 and 2015/16.

A stratified two-stage sample design was adopted in all three countries. Within each stratum (urban and rural regions, districts or states, depending on the country), the primary sampling units were Enumeration Areas (EAs) selected with a probability proportional to size. Within each EA, a random systematic sampling procedure was adopted to select households to be surveyed.

The attrition rate at the household level is fairly low overall. Between the first and second round the Malawian sample reported an attrition rate of $3.78 \%$ and the Nigerian sample $4 \%$ at the household level. The Tanzanian sample reported an attrition rate of $3 \%$ between the first and second round, $3.5 \%$ between the second and third round and roughly $4 \%$ between the third and fourth round.

For the purpose of this study I select the first two Malawian data collection rounds (2010/11 and 2013) along with the first two Nigerian data rounds (2010/11 and 2012/13) and the second and third data round for Tanzania (2010/11 and 2012/13). I exclude the first Tanzanian data round as the household questionnaire does not contain a food security scale. The size of the panel dataset with no missing information for the main variables of interest and controls corresponds to 4,285 Malawian households, 15,653 Nigerian households and 6,139 Tanzanian households.

7 The LSMS-ISA questionnaire has also been administered recently in Burkina Faso, Ethiopia, Mali, Niger and Uganda. I have excluded those countries from the analysis for the following reasons: (i) they do not include a food security scale (Uganda), (ii) they have only one data round (Mali), (iii) they use a different scale (Niger) or (iv) the data were not available when this analysis was conducted (Burkina and Ethiopia). 


\subsection{Variables of interest}

The main variables of interest are measured at the household level in each data round. The analysis focuses on food security scale scores, adult equivalent food expenditures, adult equivalent caloric intakes and food diversity.

Table 1 reports the list of questions contained in each country's food security scale. There are slight differences from one country to the next. The Malawian and Tanzanian scale contains a binary question on the psychological dimension of food insecurity, i.e. worrying about not having enough food. However, the Malawian scale does not contain any questions on food variety or the most extreme conditions of food insecurity. Lastly, the Tanzanian scale does not report whether any member of the household went to sleep hungry because of there being no food at home.

Aside from the binary question on worrying about food, all other questions can be answered in terms of the number of days in the past seven days a household has experienced a certain condition. For each question, the possible values range from 0 (the condition never occurred) to 7 (the condition occurred every day). The total scale score is obtained by summing up all the positive responses. The higher the score, the less food secure the household. In the empirical analysis I reverse the score so that higher scores correspond to higher food security and then standardize it to ease interpretation of the regression results.

Food expenditures measure the monetary value of the food consumed by the household in the past seven days. It includes food purchases, home-produced food, food received as a gift and food eaten outside of the home. I obtain a measure of unit value by dividing the value of food purchases by their quantity in order to impute the value of home-produced food and food received as a gift, for which no information on value is otherwise provided. For ease of comparison of magnitudes across countries, I convert food expenditures into US dollars based on the exchange rate of the same calendar year as data collection.

The measure of caloric availability is constructed by assigning calories to the amount of food consumed in the past seven days. Caloric availability appears to suffer from large measurement error biases in the Nigerian and Malawian data due to lack of conversion factors for the food quantity units of measure used in the questionnaire. This gives rise to an underestimation of the true values $(1,500 \mathrm{kcal}$ per person per day on average in the Malawian data and 1,521 kcal in the Nigerian data). This analysis, hence, considers caloric availability for the Tanzanian data only. I use the Tanzania Food Composition Tables to translate food quantities into kilo-calories. I rescale the amount of food consumed into grams since the kilo-calories reported in the food composition tables refer to grams. For ease of interpretation of the regression results, I divide the caloric intakes by 1000 .

To take into account household size, I divide both food expenditures and caloric availability by the number of equivalent adults. Given that these measures may be subject to measurement error, I trim both measures at the top and bottom $5 \%$ to prevent the results being driven by extreme values. 
Lastly, food diversity is measured in terms of the number of food groups consumed by the household in the past seven days. This number ranges from 1 to 12, in line with the Household Diet Diversity Score and the World Food Program Consumption Score (Swindale and Bilinksy (2006), Ruel (2002), Weismann et al. (2009)).

\section{$2.2 \quad$ Descriptive statistics}

I first investigate the assessment of the food security condition in each country provided by the variables of interest by looking at the first and second moments of their distributions. Table 2 reports the sample mean, median and standard deviations for each food security measure and for a set of household characteristics associated with household food security. ${ }^{8}$

Descriptive statistics show a fairly constant pattern across countries in terms of scale scores and food diversity. The average scale score is negative and around -3 in all three countries, though the 50th percentile equals zero, meaning that at least half of the sample is actually food secure according to the food security scale. Similarly, the number of food groups is fairly high across all countries, at an average of 8 groups out of 12 , and the median value is fairly close, suggesting a symmetric distribution.

Food expenditures, in turn, exhibit remarkable differences across countries. Nigeria reports the highest average food expenditures per adult equivalent $(\$ 11.37)$, with a median value and standard deviation of $\$ 9$. Even though this is the highest sample mean of the three countries, when reported on a daily basis it corresponds to barely $\$ 1.6$ per adult equivalent per day. In Malawi and Tanzania average food expenditures for the past seven days come to about $\$ 8$.

Turning to food expenditures, the statistics reported in Table 2 for caloric availability per adult equivalent are measured for the past seven days. On a daily basis, the mean for the Tanzanian sample corresponds to 2,100 kcal per adult equivalent per day.

The low food expenditure values reflect a widespread poverty condition. Almost half of the Tanzanian sample spends less than $\$ 1.25$ per adult equivalent per day for their food consumption. The same holds true for $44 \%$ of the Malawian sample and $33 \%$ of the Nigerian sample (the median values are slightly higher). In terms of other household characteristics relevant to the food security condition, the data show that the number of young children under five years old is lower on average in Tanzania (0.46) than in Malawi and Nigeria (1), whereas asset wealth is higher in Tanzania than in the other two countries.

A closer look at the distribution percentiles of the food security measures reveals different proportions of food insecure households, depending on the measure considered. Two-thirds of the Tanzanian (65\%) and Malawian (67\%) sample spend less than $\$ 1.25$ per adult equivalent per day on their food expenditures, while the share is $46 \%$ for the Nigerian sample. By contrast, the cross-country food insecurity figures are strikingly similar when it comes to the scale score. The share of households reporting at least one of the scale items comes to $58 \%$ in Tanzania and

\footnotetext{
${ }^{8}$ Scale scores are not standardized in this Table but are inverted to be in line with the other food security measures. In this Table, the maximum value of the scale is 0 while negative values indicate low food security.
} 
$56 \%$ in Nigeria and Malawi. Lastly, the share of households consuming less than 2,100 kcal per adult equivalent per day in terms of caloric availability comes to $53 \%$ in Tanzania.

These figures show that the three measures do not always concur when it comes to the share of food insecure households in each country. With respect to food expenditures, the scale detects a lower share of food insecure households in Tanzania and Malawi, but a higher proportion in Nigeria. With respect to caloric availability, however, the scale reports a slightly higher proportion of food insecure households in Tanzania.

These discrepancies may be due to a divergence in the dimensions of food security captured by each measure. Aspects such as food access, food quality, food quantity and food preferences may be captured by some but not all measures. For instance, a larger share of food-insecure households in terms of food expenditures might indicate a considerable lack of food access. Yet accounting for food preferences and diversity might deliver a lower estimate of food insecurity, as is the case for Tanzania and Malawi. The merits of using food security scales may be found precisely in their potential capacity to capture aspects of food security missed by standard measures.

\section{$2.3 \quad$ Non-parametric estimates}

To investigate the functional form of the relationship between the food security scale and the other measures, I first use a non-parametric analysis. Figures 1 and 2 report the non-parametric estimates of the relationship between the food security scale z-scores, food expenditures and caloric availability per adult equivalent based on the Tanzanian sample. ${ }^{9}$ The 25 th, 50 th and 75th percentiles of the distributions are marked with red vertical lines for ease of interpretation.

In both cases, the figures point to a positive link between the scale scores and the other two measures. In the case of food expenditures, the relationship displays a logarithmic pattern up to roughly $\$ 13$ per adult equivalent, when it starts to level off (Figure 1). Caloric availability presents a much weaker relationship (Figure 2) with a flat curve, suggesting no significant correlation between caloric availability and the food security scale scores.

There could be a number of reasons for the lack of a positive correlation for the upper parts of the distributions illustrated by the two Figures. First, the conditions listed in the scale might only mean something to deprived households, and not apply to better-off households. If this were the case, a much larger proportion of households in the upper part of the distribution would not report any scale item. Yet, $67.5 \%$ of those with food expenditures over $\$ 13$ do not report any scale condition, which is not that far off from the $58.2 \%$ of those spending less than $\$ 13$. Similarly, $59.9 \%$ of those above the median value of caloric availability do not report any scale condition compared to $59.6 \%$ of those below the median value.

Another explanation could be that the scales capture other dimensions of food security that food expenditures and food calories do not measure, and that this difference is greater for households in the upper part of the distribution. In other words, households at the bottom

\footnotetext{
${ }^{9}$ Similar patterns are found for the other two countries and results are available on request.
} 
of the distribution are food insecure under all dimensions, whereas households further up the distribution are insecure under certain dimensions but not all. The lack of correlation for the upper part of the distribution might suggest that different dimensions are involved and, hence, that different indicators may be needed.

Lastly, the correlation estimates might be rendered less accurate by too much noise in the data for the upper part of the distributions of food expenditures and caloric availability. It might, for instance, be harder for wealthier households to correctly recall exact amounts, as they probably spend more and buy more types of food. Alternatively, if wealthier households are more educated, they might keep better track of household expenditures, making their answers more accurate. If this measurement error were constant over time, it would be dealt with by household fixed effects. Similarly, fixed effects would solve measurement error due to questionnaire design, since it is constant across survey rounds. This would make a case for using food security scales in household surveys, as their ease of administration might well reduce the amount of noise in the data.

\section{Methodology}

Before exploiting the panel dimension of the data, I conduct a cross-section analysis separately for each data round in each country to estimate the correlation in terms of levels between the food security scale and the other three measures. This provides a snapshot of the correlation between these measures at a given point in time.

The regression estimated for country $c$, household $i$ is:

$$
F S_{c, i}=\alpha_{0}+\alpha_{1} F C_{c, i}+X_{c, i}^{\prime} \beta+\epsilon_{c, i}
$$

where $F S$ is the z-score for the household food security scale, with higher values indicating higher food security. $F C$ is one of the following food security measures: adult-equivalent food expenditures, adult-equivalent caloric availability and food diversity. $X^{\prime}$ is a vector of household characteristics measured by each data round that may affect food security: number of children under five years old, value of assets and a monetary poverty dummy equal to one if total adultequivalent daily expenditures are below $\$ 1.25$. The standard errors $\epsilon_{c, i}$ are clustered at the enumeration area level to account for the sample design.

As shown by the non-parametric estimates reported in Figures 1 and 2, the relationship between scale scores, food expenditures and caloric availability appears to be non-linear. It is positive, stronger and fairly linear for households below the median value of caloric availability and food expenditures, but tends to level off thereafter and becomes more imprecise in the upper part of the distribution. I use the logarithmic form of food expenditures and caloric availability 
to take into account these non-linearities. ${ }^{10}$

The analysis then explores the correlation between the changes in the food security measures using the panel structure of the data. The regression estimated for country $c$, household $i$ at time $t$ is as follows:

$$
F S_{c, i, t}=\alpha_{0}+\alpha_{1} F C_{c, i, t}+X_{c, i, t}^{\prime} \beta+\delta_{c, i}+\mu_{c, t}+\epsilon_{c, i, t}
$$

$X^{\prime}$ now varies over time. By adding this set of characteristics, I can control for changes in household living conditions which may be correlated with changes in household food security between the two data rounds. For instance, households increasing their wealth may reduce their food expenditures if food is an inferior good, and yet they may worry less about food and appear more food secure in terms of the scale. Lastly, household fixed effects are captured by $\delta_{c, i}$, year fixed effects by $\mu_{c, t}$ and the standard errors $\epsilon_{c, i, t}$ are clustered at the enumeration area.

The interpretation of $\alpha_{1}$ in (2) differs from Equation (1) in that $\alpha_{1}$ now captures the correlation between deviations from the mean in the food security scales and deviations from the mean of the other three measures. The main purpose of this approach is to assess the capacity of the set of measures to capture changes in household food security over time. Considering all the permanent household-specific conditions impacting food security and after controlling for some observable time-varying factors, does a change in food expenditures, caloric availability or food diversity correspond to a change in the food security scale scores? This question is policy relevant, given the importance of monitoring food security trends to evaluating the effectiveness of food insecurity mitigation interventions. Measures are particularly useful if they also capture changes in food security across space and time, whether in terms of food quantity, food quality or food preferences.

Controlling for household and year fixed effects nets out the correlation between food security measures and unobservable aspects that may affect food security at the household level and that can be considered as fixed between the two data rounds. These may include, for instance, geographical features, long-term vulnerable living conditions, market access and fixed behavioral traits at the household level. In addition, the year fixed effects control for unobservable features constant across households and within each data round, such as the time trend, business cycle or aggregate shocks that may impact food security. Moreover, I control for time-varying household characteristics, such as asset wealth and monetary poverty, which may be correlated with the regressors of interest.

Unobservable fixed characteristics may, indeed, matter for the correlation between food security measures. For instance, households living in remote areas might rely more on their own food production, which may be of lower monetary and caloric value and less diversified than food purchased on the market. Yet, less dependency on the markets might protect them from the risk of price inflation and make it easier to smooth consumption, which could give rise to a

${ }^{10}$ Results using the linear form of food expenditures and caloric availability while controlling for their squared term confirm the results obtained with the logarithmic form and report a negative estimated coefficient for the squared term. 
better food security condition as measured by the scale. In this case, omitting households and year fixed effects would bias the estimates downwards.

It is worth pointing out, moreover, that introducing fixed-effects helps reduce omitted variable bias and measurement error bias, if this is serially correlated (Freeman, 1984). The two biases can play in the same or opposite directions. The first can bias the cross-section estimates upwards or downwards, depending on the correlation between the regressors and the unobservable fixed-effects. The second can bias the cross-section estimates downwards.

The main assumption behind the fixed effects estimator is that a variation in food expenditures, caloric availability or food diversity is independent of the error term conditional on fixed effects and household controls. This assumption will be violated if time-varying unobservable factors, such as idiosyncratic shocks and changes in market access and preferences, affect one of the three regressors of interest. This is a major caveat when it comes to interpreting the set of results. Yet it is reasonable to assume that the effect of time-varying factors on household food security will work in the same direction, whichever way food security is measured. For instance, a bad harvest season will lower the amount of available food, thereby reducing caloric availability, food expenditures and, most likely, scale scores. In this case, the sign of the correlation will not be affected. Nevertheless, the magnitude of the effect of unobservable random shocks on each single measure may differ, affecting the size of the correlation with the dependent variable differently.

I use a regression analysis to further explore the non-linearities identified by Figures 1 and 2 , testing whether the link between the food security scale and the other three measures is driven by part of the household expenditures distribution. Given the non-parametric results, I expect the measures to display a stronger correlation for households in the lower part of the distribution. To test this hypothesis, I create two sub-samples based on whether the level of per capita expenditures is above or below the $\$ 1.25$ poverty line in the first round.

Lastly, to further investigate the scale's contribution to measuring food security, I assess the correlation between each scale item and the other three measures using each single item as a dependent variable when running regression (2). This enables me to explore which food security conditions, as measured by the scale, are in line with or differ from the other measures. As explained above, the scale is build from a list of questions designed to capture different aspects of food security. The higher an item's value, the less food secure the household, since the item's food insecurity condition has occurred at least once in the past seven days.

The econometric models described above are not designed to estimate a potential causal effect of food security measures on food security scale scores. Instead, the empirical strategy aims at understanding the amount of variation in the food security scales that can be explained by other common measures of food security, be it in terms of levels or changes over time. If all these measures capture the same aspects of food security, then a high level of correlation should be found. Alternatively, if the measures differ in their assessment of food security conditions, then the level of correlation should be low. 


\section{Cross-section results}

The first set of results concerns the cross-section analysis conducted for each country and year to explore whether the different measures of food security are well correlated in terms of levels for each country at a certain point in time.

Based on the Malawian sample, Panel A in Table 4 shows that food expenditures, caloric availability and food diversity are all positively correlated with the food security scale scores. Households with $10 \%$ higher food expenditures are also more food secure according to the scale by $0.2544 * \ln (1.10)=0.02$ standard deviations in the first data round and by $0.4601 * \ln (1.10)=0.04$

standard deviations in the second data round. The magnitudes of the correlations are higher for food diversity. One additional food group is associated with an additional 0.14-0.16 standard deviations of the food security scale score.

The positive and significant correlation between the scale and food expenditures is confirmed for the Nigerian sample, while food diversity exhibits a negative correlation (Panel B, Table 4). Households with 10\% higher food expenditures are also 0.009-0.02 standard deviations more food secure according to the scale. Surprisingly, one additional food group is associated with a food score that is lower by about -0.02 standard deviations.

Results for Tanzania are in line with those of the other two countries (Panel C of Table 4). Households with $10 \%$ higher food expenditures are 0.02 standard deviations more food secure according to the scale in both rounds. The magnitude of the correlation for Malawi is also higher with respect to food diversity. One additional food group is associated with being 0.080.06 standard deviations more food secure. Caloric availability, in turn, is not significantly correlated with the scale scores.

These results are remarkably similar across countries, with the food security measures, in particular food expenditures, displaying a positive and significant correlation with the scale. The magnitudes are quite close, albeit fairly small, across countries. In addition, the adjusted $R^{2}$ statistic indicates that the different measures explain a mere $2.3 \%$ to $8.7 \%$ of the variation in scale scores. This means that there is a level of concurrence between the scale and the other measures, but that the scale probably also captures some other dimensions that are not picked up by the other standard measures.

I run the same regressions as a further check, pooling the two rounds for each country sample and controlling for time-varying covariates and round fixed effects. This increases sample size and, hence, the accuracy of the estimates, while controlling for round-specific effects. The results reported in Table 5 confirm the previous findings, in terms of both magnitudes and the statistical significance of the estimated coefficients. The amount of variation in the scale scores explained by the other measures ranges from $1.2 \%$ to $5.9 \%$, as indicated by the adjusted $\mathrm{R}^{2}$ statistic. These results suggest that an unobservable time-trend is not biasing the correlation between the food security indicators. 


\section{$5 \quad$ Fixed effects results}

It is worth looking into whether the scale correlates with the other measures not only in terms of its level at a given point in time, but also in terms of changes in household food security over time. The fixed-effects analysis makes use of the panel dimension of each country's data to investigate whether changes in one of the three food security measures are correlated with changes in the food security scale score. I conduct this analysis first considering the total scale score and then each single item's score.

Second, I further investigate the non-linearities discussed in section 2, testing whether the link differs along the household expenditure distribution by dividing the sample into 'poor' and 'non-poor' households. Lastly, I explore the scale's capacity to detect the vulnerability dimension of food security by testing its correlation with the Consumption Adequacy Question, a self-assessed measure in the Malawian questionnaire that captures the vulnerability dimension of food security.

Table 6 reports the results of regression (2) for Malawi, Nigeria and Tanzania. Overall, the results obtained with the fixed-effects estimator confirm the positive and significant correlation of the food security measures with the scale. The magnitudes of the correlations are smaller compared to the cross-section results, suggesting that cross-section OLS estimates are upward biased due to a positive correlation between the regressors and household fixed effects. At the same time, this also suggests that measurement error is not fully driving the previous results, as they would otherwise be affected by a downward bias. Regarding the precision of the estimates, the standard errors are roughly the same magnitude in both the cross-section and panel results.

The results for the Malawian sample (Panel A, Table 6) are in line with the cross-section results. Households increasing their food expenditures by $10 \%$ between the two data rounds also report a 0.01 standard deviation higher scale z-score. In common with the cross-section results, the correlation is much higher for food diversity. One additional food group is associated with 0.09 standard deviations more.

Nevertheless, less than $2 \%$ of the variation observed in the changes in scale scores is explained by changes of the other food security measures, as indicated by the adjusted $R^{2}$ statistic. This is lower than the adjusted $R^{2}$ statistic reported by the cross-section results in Panel A of Table 4 and Table 5 (between $2 \%$ and $9 \%$, depending on the measure).

These results are echoed by those obtained with the Nigerian sample (Panel B, Table 6). A positive variation of $10 \%$ in food expenditures per adult equivalent is associated with a 0.009 standard deviation higher scale z-score. The estimated coefficient for food diversity is positive but not statistically significant, suggesting that the significant link detected by the cross-section analysis was due to a spurious correlation between regressors and household fixed effects.

In turn, the importance of household unobservable factors is less stringent in the Tanzanian case. The cross-section results are confirmed, although the magnitudes of the estimated coefficients are smaller. A 10\% increase in food expenditures between the two data rounds is associated with a 0.01 s.d. higher scale z-score (Panel C, Table 6). Moreover, increasing food 
diversity by one additional food group is associated with a 0.04 s.d. higher z-score, while the correlation with a variation in caloric availability is positive but not significant, as with the cross-section results.

Overall, these results suggest that changes in scale scores positively correlate with changes in the other food security measures over time, in particular food expenditures and food diversity. Yet the magnitudes of the estimated coefficients are fairly small and the amount of variation in the scale scores explained by the other food security measures is also quite small, as shown by the adjusted $R^{2}$ statistics. It is worth pointing out that controlling for changes in the household poverty condition, measured by a monetary poverty dummy, does not affect the correlation between changes in the food security measures and scale scores, as would be expected if the four food security measures all varied in a similar way. Moreover, the poverty dummy's lack of significance suggests that changes in the scale do not merely capture changes in household deprivation status.

\subsection{Heterogeneity analysis}

The cross-section and panel analysis find a significant, albeit small, correlation between the scale and the other three measures, suggesting some level of overlap in measuring food security. As indicated by the Kernel-weighted local polynomial smoothing reported in Figures 1 and 2, the level of agreement among food security variables might actually vary along their distribution. The graphs suggest that households with low food expenditures or low caloric availability are also deemed insecure by the scale. Yet, the correlation is much weaker in the upper part of the distribution. This subsection further explores these non-linearities, investigating whether the correlation between the food security measures differs according to the poverty status of the respondents.

The analysis is conducted based on the household poverty condition measured using adultequivalent daily expenditures as reported in the first data round of the LSMS-ISA. A household is defined as being poor if these expenditures are below the $\$ 1.25$ poverty line. While poor households are not necessarily food insecure, what might matter most in terms of food security is the share of food expenditures out of total expenditures, rather than food expenditures themselves. A higher share of food expenditures may be associated with higher caloric availability and food diversity, even though the subjective assessment of food security may actually be worse. Rather than directly controlling for total household expenditures, which are strongly correlated with food expenditures, or taking the ratio of food expenditures to total expenditures, which would be hard to interpret, I choose to divide up the sample by household poverty level.

Table 7 Panel A shows that the correlation between the scale and the other two measures is driven by the sub-sample of poor Malawian households (columns 1 and 3), echoing the nonlinearities revealed by the non-parametric estimates. For this sub-sample, a $10 \%$ increase in food expenditures per adult equivalent is associated with 0.01 standard deviation higher scale z-score. In turn, changes in food diversity appear to be significantly correlated with the scale 
scores of both sub-samples. One additional food group is associated with a 0.1 s.d. higher scale z-score for the poor sub-sample and 0.06 s.d. more for the non-poor sub-sample.

By contrast, in the case of Nigeria, the association between food expenditures and the scale is larger for the sub-sample of non-poor households, 0.01 s.d against 0.008 s.d. for the poor sub-sample (Panel B, Table 7). In turn, food diversity proves to significantly correlate with the scale only for the sub-sample of poor households (+0.01 s.d., column 3$)$.

In line with the results for Malawi,the positive and significant correlation between the scale and the other measures is also driven by poor households in the Tanzanian sample (Panel C, Table 7). A 10\% increase in food expenditures and one additional food group are associated with, respectively, a 0.02 s.d. and 0.08 s.d. higher scale z-score. The results for caloric availability are not significant, as with the cross-section results.

By and large, these results are line with the non-parametric estimates. The correlation between the scale and the other measures of food security is higher for poor households, whereas it is lower for less deprived households. These findings are unlikely to be driven by measurement error as household fixed effects are accounted for in all regressions. Moreover, it is worth pointing out that the larger size of the non-poor sub-sample and the equal magnitude of the estimated standard errors indicate that the lack of significant results for the non-poor sub-group is not due to a lack of statistical power.

\subsection{Scale items}

I assess the correlation between each single scale item and the other three measures to investigate which dimensions of the scale are significantly associated with changes in the other food security measures. Given that the scale is a statistically valid measure of food security, what dimensions of food security included in the scale are poorly captured by the other measures? In other words, what aspects of food security does the scale capture over and above those already measured by food expenditures, caloric availability and food diversity?

Each item reports the number of days in the past seven days that a household has experienced the condition described by the item itself. The higher the item's value (ranging from 0 to 7 ), the less food secure a household, since the household has experienced that particular condition at least once in the past week. Figures 3, 4 and 5 report the results obtained by regressing each item separately on food expenditures, food diversity and caloric availability, while controlling for household and year fixed-effects. ${ }^{11}$

In line with the main results, Figure 3 shows that higher food expenditures and food diversity are associated with lower food insecurity for each scale item. The correlation is negative for all the different items, suggesting that, on average, the conditions listed in the scale are all in keeping with low food expenditures and low food diversity.

On average, a 10\% increase in food expenditures between the two data rounds is significantly associated with a 0.1 percentage point decrease in worrying about food (item 1), 0.31 fewer days

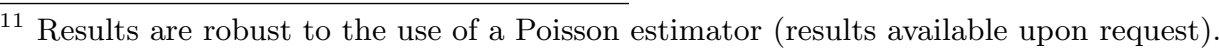


of food insecurity in terms of relying on less preferred food (item 2) and 0.14 fewer days of having to reduce the number of meals (item 4). The correlation with items 3,5 and 6 is also negative, but not significant. What is the magnitude of these effects? Compared to the sample mean, the decrease is $-3 \%$ for item 2 (consuming less preferred food) and $-2.7 \%$ for item 4 (reducing number of meals), while it corresponds to $-33.3 \%$ for item $1 .{ }^{12}$

These results are confirmed also with respect to food diversity, but the correlations are much higher in this case. One additional food group is associated with a $20 \%$ decrease in items 3,4 and 5 (reducing portion size, reducing the number of meals and restricting adult consumption for the benefit of children), a 17\% decrease in item 6 (borrowing food), a 14\% decrease in item 2 (eating less preferred food) and a $13 \%$ decrease for item 1 (worrying about food). Overall, these results suggest that there are three scale items that significantly correlate with the other measures: worrying about food (item 1), consuming less preferred food (item 2) and reducing the number of meals (item 4).

Results for the Nigerian sample paint a different picture from the analysis of the overall score. The item-by-item analysis reveals a number of dimensions that are significantly correlated with the other measures (Figure 4). In particular, the items capturing the most extreme food insecurity conditions are the most closely correlated with food expenditures and food diversity. Compared to the sample average, a $10 \%$ increase in food expenditures is associated mainly with a $-2.4 \%$ decrease in terms of item 9 (going a whole day and night without eating), a - $2 \%$ decrease in terms of item 5 and 8 (restrict adult consumption for the benefit of the children and going to sleep hungry), a $-1.4 \%$ decrease in terms of item 3 and 6 (reducing portion size and borrowing food), and a $-1 \%$ decrease in terms of item 1, 2 and 4 (consuming less preferred food, limiting food variety and reducing number of meals).

Similarly, food diversity correlates particularly well with the most extreme items. Compared to the sample average, consuming one additional food group between the two data rounds is negatively associated with having no food at home and going to sleep hungry ( $-8 \%$ for items 7 and 8), borrowing food and going a whole day and night without eating (-7\% for items 6 and 9), restricting adult consumption for the benefit of the children $(-3.3 \%$ for item 5$)$ and reducing the number of meals $(-2.5 \%$ for item 4$)$. Interestingly, changes in food diversity do not significantly correlate with changes in food preferences and variety (items 1 and 2).

All in all in the Nigerian case, the two items constantly correlated with the other three measures appear to be the two most extreme items: going to sleep hungry (item 8) and going a whole day and night without eating (item 9).

The analysis of the Tanzanian sample finds that a range of items are significantly associated with the other three measures (Figure 5). Relative to the sample mean, a $10 \%$ increase in food expenditures between the two data rounds is associated with a decrease in worrying about food $(-12.5 \%$, item 1$)$, going a whole day and night without eating $(-7.6 \%$, item 9$)$, having no food at home $(-4 \%$, item 8$)$, reducing portion size $(-2.7 \%$, item 4$)$, having to eat less preferred food and reducing the number of meals $(-2 \%$, items 2 and 5$)$.

\footnotetext{
$\overline{12}$ Item 1 on the Malawian scale is a binary variable, rather than a categorical variable as the other items. See Table 1.
} 
Previous results reported in Table 6 show that caloric availability is not significantly correlated on average with the overall scale score. Yet, a look at each single item reveals that changes in the extreme conditions measured by items 8 and 9 significantly correlate with changes in caloric availability per adult equivalent. A $10 \%$ increase in available food calories is associated with a $-7.4 \%$ decrease in the number of days without any food at home (item 8 ) and a $-12 \%$ decrease in going a whole day and night without eating (item 9). Even though the point estimates for the other items are not statistically significant, they are all negative, except for items 3 and 5.

The scale items for the Tanzanian sample also present a higher correlation with food diversity than with food expenditures and caloric availability. One additional food group is associated with lower food insecurity in terms of items 8 and 9 (-25\%, going a whole day and night without eating and having no food), item 7 ( $-13 \%$, borrowing food), items 2,4 and 5 ( $-8 \%$, consuming less preferred food, reducing portion size and reducing the number of meals) and item $1(-4 \%$, worrying about food). Much like the Nigerian sample, the two items that correlate the most with the other measures are those relating to the most extreme conditions of food insecurity: having no food at home (item 8) and going a whole day and night without eating (item 9).

All in all, these results suggest that several conditions listed on the scale significantly correlate with the three food security measures. Three aspects are worth pointing out in particular. First, the largest magnitudes are found for food diversity, which may suggest that the scale is more in line with aspects relating to food variety than the monetary and caloric value of the food consumed.

At the same time, the conditions that correlate the most (or most often) with the other measures are the aspects pertaining to chronic insecurity and worrying about food. Having no food at home and going a whole day and night without eating are the two items that constantly report the highest correlations relative to the sample mean with all the other three measures in Tanzania and Nigeria (the Malawian scale does not contain these two items). These dimensions identify households with a chronic insecurity condition that, in line with the non-parametric estimates, probably lie in the bottom of the food expenditures and caloric availability distributions. Moreover, the Malawian and Tanzanian sample results show that the psychological dimension of worrying about a lack of food correlates significantly with food expenditures (the Nigerian scale does not contain this item). This suggests that the dimensions relating to extreme and psychological food insecurity overlap the most with the other three measures.

Dimensions relating to less extreme coping strategies than going a whole day and night without eating are, in turn, more loosely correlated with the other standard measures. For instance, the strategies of changing the diet by reducing food variety, rationing food by reducing the number and frequency of meals, restricting adult consumption and relying on safety nets to borrow food, all report much smaller correlations. This suggests that taking into account these conditions paints a more accurate picture of the household's experience of food insecurity and, in particular, of the behavioral response to lacks of food quantity, food quality or food variety, making the scale a valuable complementary indicator. 
Third, no item appears to be constantly unrelated to the other measures. In the Malawian and Tanzanian sample, the only condition that does not correlate with the other measures is the intra-household redistribution of food (restricting adult consumption for the benefit of the children). In addition, the food variety dimension (item 3) does not appear to be significantly related to any of the other three measures in the Tanzanian sample. No item in the Nigerian sample systematically presents a non-significant correlation with the other measures, even though reducing portion size (item 4) reports the smallest correlation relative to the sample mean. This suggests that the scale may capture some country-specific aspects of food security (intra-household distribution of food in Malawi and Tanzania, food variety in Tanzania and portion size in Nigeria) that are somehow missed by food expenditures, caloric availability and food diversity.

\subsection{Food vulnerability}

The last step of this analysis consists in exploring the scale's capacity to capture food vulnerability, a dimension of food security not directly addressed by any item, despite being a key component of household food security. I therefore investigate its correlation with another selfassessed measure of food security, the Consumption Adequacy Question (CAQ), which focuses on the vulnerability dimension of food security. If the scale's correlation with the CAQ measure is stronger than with the other measures, this would suggest that the scale also captures the vulnerability dimension, providing additional valuable information about household food security that is not directly accounted for by any of the other standard measures.

Of the three countries considered in this study, the CAQ measure is found only in the Malawian LSMS-ISA questionnaire. Its statistical validity has been confirmed by Migotto et al. (2005) and Carletto and Zezza (2006) using data collected in Albania, Indonesia, Madagascar and Nepal. Their studies have shown that the CAQ adequately captures the vulnerability component of food security.

The Consumption Adequacy Question is expressed as follows:

"Concerning your household's food consumption over the past one month, which of the following is true?"

$1=$ It was less than adequate for household needs

$2=$ It was just adequate for household needs

$3=$ It was more than adequate for household needs

The answers reported in the data present considerable variations. In the first data round, some $34.3 \%$ of households reported that food consumption was less than adequate, $58.4 \%$ reported that it was just adequate and $7.3 \%$ reported that it was more than adequate. Similar questions were also asked with respect to housing conditions, household clothing and standards of healthcare received.

Results reported in Table 8 show that the scale overlaps much more with the Consumption Adequacy Question than with food expenditures and diversity. The estimated coefficient is 
0.4, much larger than the one of the other two measures. Simply adding in the CAQ measure raises the adjusted- $R^{2}$ from 0.02 (as reported in Table 6) to 0.08 . The correlation between food expenditures and food diversity and the scale remains positive and significant, but smaller than in previous results. Compared to the findings reported in Table 6, the point estimates decrease by roughly 0.04 percentage points for food expenditures and by $0.02 p p t s$ for food diversity.

To investigate which scale's conditions correlate the most with the CAQ measure, I explore its association with each scale item, while controlling for household time-varying aspects (number of young children, asset wealth and monetary poverty), and household and year fixed effects. Results reported in Figure 6 show a significant and negative relationship with all scale items. In particular, worrying about food is associated with a 0.4 ppt decrease in the CAQ measure, which corresponds to $82.6 \%$ of the sample mean. The correlation is extremely high for items 3,4 and 5 (-90\%, reducing portion size, reducing number of meals and restricting adult consumption). Items 2 and 6 also show a statistical and negative correlation of $-60 \%$ compared to the sample mean. This suggests that a large part of the food security vulnerability dimension has to do with worrying about running out of food, but also food rationing and intra-household redistribution. Overall, these results indicate that the scale captures the vulnerability dimension of food security and that it does so better than the other standard measures.

\section{Conclusions}

Despite food security having been high on the development agenda for the past 70 years, there is still much debate surrounding its measurement. A new type of measure, the food security scales introduced by the nutritionist literature in the 1990s, has recently gained currency with the international community for its capacity to capture multiple dimensions of food security.

These food security scales have been adopted far and wide by surveys all over the world and their internal statistical validity has been widely assessed. Yet there is still little evidence of their capacity to improve the measurement of food security compared to standard measures, such as food expenditures, caloric availability and food diversity.

This paper contributes to the literature on the measurement of food security by investigating the correlation between a food security scale and other food security measures over space and time. Drawing on nationally representative LSMS-ISA household panel data from Malawi, Nigeria and Tanzania, this study is, to the best of my knowledge, the first to explore the added value of a food security scale administered in different countries over a space of time by comparing it to standard measures of food security across countries and over time.

The main set of results shows that fear of running out of food and some of the most extreme conditions of chronic food insecurity listed on the scale correlate well with the other standard measures. The scale appears in turn to capture food vulnerability and rationing strategies dimensions missed by the other measures. Aspects such as a change of diet by reducing food variety, rationing food by reducing the number and frequency of meals, restricting adult consumption, and relying on safety nets to borrow food, are all conditions captured by the scale 
that present little overlap with the standard measures. This makes the scale a useful indicator for providing a more accurate description of the behavioral responses and household dynamics characteristic of food insecurity.

The main results appear to be explained by the sub-sample of households living with less than $\$ 1.25$ a day, suggesting that the link between the four measures is particularly strong when measuring the food security status of the most deprived households. The use of household and time fixed effects makes these results less likely to be driven by pure measurement error.

In conclusion, these findings suggest that the scale captures aspects of food security associated in particular with food vulnerability and food insecurity coping strategies, which are not captured by the standard measures. This makes the scale a valid complementary indicator to improve the measurement and understanding of the household food security condition, its comparison across countries and its monitoring over time. 


\section{References}

Alvarez, M. C., Estrada, A., Montoya, C., And Melgar-Quiñonez, H. 2006. Validacion de escala de la seguridad alimentaria domestica en antioquia, colombia. Salud publica de Mexico 48:474-481.

Ballard, T., Kepple, A., and Cafiero, C. 2013. The food insecurity experience scale: development of a global standard for monitoring hunger worldwide. Technical report, Technical Report, Rome, FAO.

BARREtT, C. 2002. Food security and food assistance programs. Handbook of Agricultural Economics, volume 2, chapter 40. Elsevier Science B.V.

Bezuneh, M., Yiheyis, Z., Del Rosario, P. J., And Ortiz, L. 2008. Measuring food security in the Dominican Republic adaptation of the U.S. food security survey module. Technical report, U.S. Dept. of Agriculture, Economic Research Service.

Cafiero, C., Nord, M., Viviani, S., Del Grossi, M., Ballard, T., Kepple, A., Miller, M., AND Nwosu, C. 2015. Methods for estimating comparable prevalence rates of food insecurity experienced by adults throughout the world. Technical report, Technical Report, Rome, FAO.

Carletto, G. and Zezza, A. 2006. Being poor, feeling poorer: combining objective and subjective measures of welfare in Albania. Journal of Development Studies 42:739-760.

CoAtes, J. 2004. Experience and expression of food insecurity across cultures: practical implications for valid measurement. Technical report, EC/FAO Programme on Food Security Information for Action, FANTA project.

CoAtes, J. 2013. Build it back better: Deconstructing food security for improved measurement and action. Global Food Security 2:188 - 194.

Contes, J., Frongillo, E., Rogers, B. L., Webb, P., Wilde, P. E., And Houser, R. 2006a. Commonalities in the experience of household food insecurity across cultures: what are measures missing? Journal of Nutrition 136.

Coates, J., Swindale, A., And Bilinsky, P. 2007. Household food insecurity access scale (HFIAS) for measurement of food access: indicator guide. Technical report, Washington DC. Food and Nutrition Technical Assistance II Project (FANTA-2).

Contes, J., Wilde, P. E., Webb, P., Rogers, B. L., And Houser, R. F. 2006b. Comparison of a qualitative and a quantitative approach to developing a household food insecurity scale for Bangladesh. Journal of Nutrition 136:1420-30.

Comité Cientifico De la ELCSA 2012. Escala Latinoamericana y Caribeña de seguridad alimentaria (ELCSA): manual de uso y aplicaciones. FAO, Rome. 
Deitchler, M., Ballard, T., Swindale, A., and Coates, J. 2010. Validation of a measure of household hunger for cross-cultural use. Technical report, Washington DC. Food and Nutrition Technical Assistance II Project (FANTA-2).

FAO 1996. Rome declaration on world food security. Technical report, FAO.

FAO 2008. Report on use of the Household Food Insecurity Access Scale and Household Dietary Diversity Score in two survey rounds in Manica and Sofala provinces, Mozambique, 2006-2007. Technical report, FAO.

FAO, IFAD, UNICEF, WFP, AND WHO 2017. The state of food security and nutrition in the world. Building resilience for peace and food security. Technical report, Rome, FAO.

FAO, IFAD, AND WFP 2013. The state of food insecurity in the world 2013. The multiple dimensions of food security. Technical report, Rome, FAO.

FAO, IFAD, AND WFP 2015. The state of food insecurity in the world 2015. Meeting the 2015 international hunger targets: taking stock of uneven progress. Technical report, Rome, FAO.

Fiszbein, A. And Giovagnoli, P. I. 2004. Hambre en la Argentina. Desarrollo Economico $43: 630-656$.

Food and Nutritional Technical Assistance project 2004. Measuring household food insecurity. Technical report, Academy for Educational Development, Washington DC.

FrEeman, R. 1984. Longitudinal analyses of the effects of trade unions. Journal of Labor Economics 2:1-26.

Frongillo, E. A., Chowdry, N., Exstrom, E.-C., And Naved, R. T. 2003. Understadning the experience of household food insecurity in rural Bangladesh leads to a measure differenct from that used in other countries. Journal of Nutrition 133:4158-4162.

Gulliford, M. C., Nunes, C., And Rocke, B. 2006. The 18 household food security survey items provide valid food security classifications for adults and children in the Caribbean. $B M C$ Public Health 6:1-8.

Hackett, M., Melgar-Quiñonez, H., and Alvarez Uribe, M. C. 2008. Internal validity of a household food security scale is consistent among diverse populations participating in a food supplement program in Colombia. BMC Public Health 8:1-9.

Hoddinott, J. 2001. Choosing Outcome Indicators of Household Food Security. Methods for Rural Development Projects p. 31.

Hoddinoti, J. And Yohannes, Y. 2002. Dietary diversity as a food security indicator. FCND briefs 136, International Food Policy Research Institute (IFPRI).

Kisanga, J., Miller, D., And Wadhwa, A. 2012. Comprehensive Food Security and Vulnerability Analysis. Technical report, World Food Programme. 
Maxwell, D. And Caldwell, R. 2008. The Coping Strategies Index. Field Methods manual. Technical report, World Food Programme.

Melgar-Quiñonez, H., Alvarez Uribe, M. C., Fonseca Centeno, Z. Y., Bermudez, O., Palma de Fulladolsa, P., Fulladolsa, A., Paras, A., and Pérez-Escamilla, R. 2010. Caracteristicas psicometricas de la escala de seguridad alimentaria ELCSA aplicada en Colombia, Guatemala y Mexico. Segurança alimentar e nutricional 17:48-60.

Melgar-Quiñonez, H., Zubieta, C. A., MkNelly, B., Nteziyaremye, A., Gerardo, M. F., AND Dunford, C. 2006. Household food insecurity and food expenditure in Bolivia, Burkina Faso and the Philippines. Journal of nutrition 136:1431-37.

Migotto, M., Davis, B., Carletto, G., and Beegle, K. 2005. Measuring Food Security Using Respondents' Perception of Food Consumption Adequacy. Working Papers 05-10, Agricultural and Development Economics Division of the Food and Agriculture Organization of the United Nations (FAO - ESA).

Pérez-Escamilla, R., Melgar-QuinÑonez, H., Nord, M., Alvarez, M. C., And Segall-Correa, A. M. 2007. Escala Latinoamericana y Caribeña de Seguridad Alimentaria (ELCSA). Technical report, Primera Conferencia Latinoamericana y Caribeña sobre la medicion de la inseguridad alimentaria.

Pérez-Escamilla, R., Paras, P., Acosta, M. J., Peyrou, S., Nord, M., and HromiFiedler, A. 2011. Are the Latin American and Caribbean Food Security Scale (ELCSA) items comparable across countries? The FASEB Journal 25.

Radimer, K. L., Olson, C. M., and Campbell, C. C. 1990. Development indicators to assess hunger. Journal of Nutrition 120:1544-1548.

RuEL, M. T. 2002. Is dietary diversity an indicator of food security or dietary quality? A review of measurement issues and research needs. Technical report, International Food Policy Research Institute.

A. Sen (ed.) 1981. Poverty and famines. An essay on entitlement and deprivation. Oxford University Press.

Swindale, A. And Bilinksy, P. 2006. Household dietary diversity score (HDDS) for measurement of household food access: indicator guide. Technical report, Food and Nutrition Technical Assistance Project, Academy for Educational Development, Washington DC.

United Nations 1975. Report of the world food conference. Rome 5-16 November 1974. Technical report, United Nations, New York.

Weismann, D., Bassett, L., Benson, T., And Hoddinott, J. 2009. Validation of the World Food Programme's Food Consumption Score and alternative indicators of household food security. Technical report, International Food Policy Research Institute. 


\section{Figures}

Figure 1: Food security scale z-scores and food expenditures. Tanzania first data round

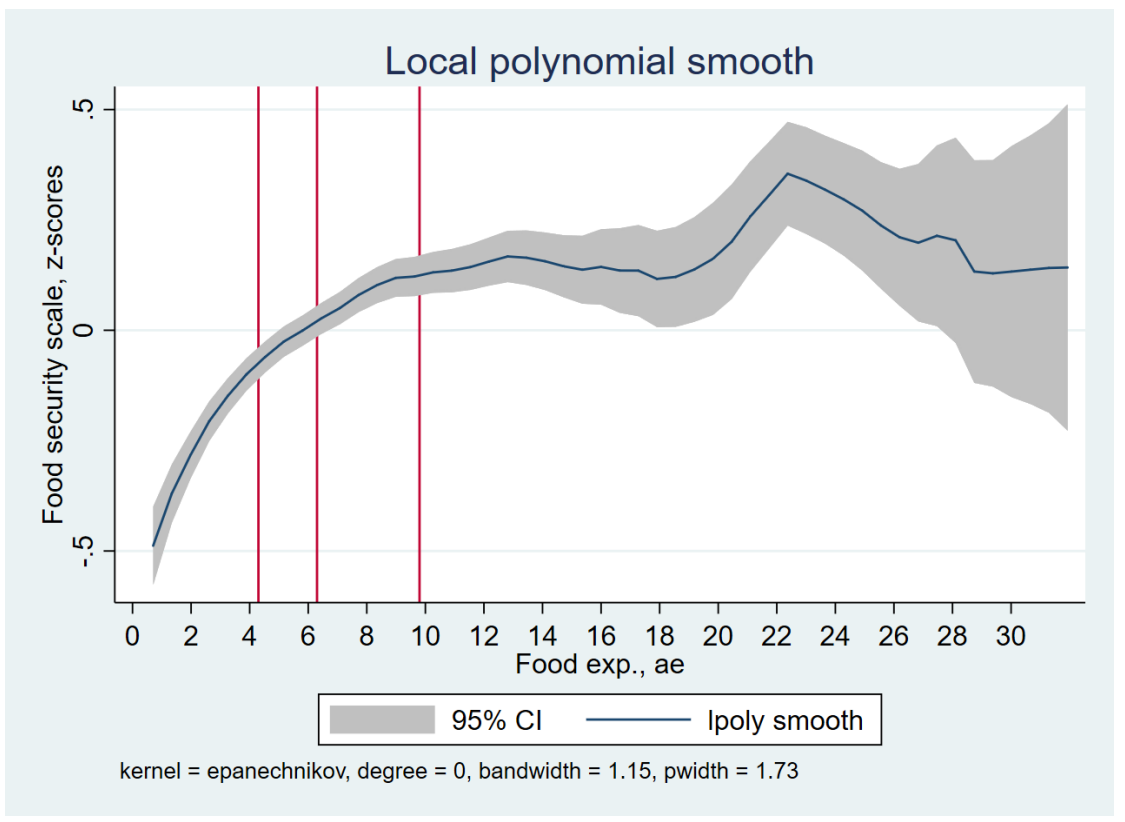

Note: Scale z-scores and food expenditures refer to the past 7 days. Food expenditures are measured in terms of adults equivalent and expressed in 2011 US dollars.

Figure 2: Food security scale z-scores and caloric availability. Tanzania first data round

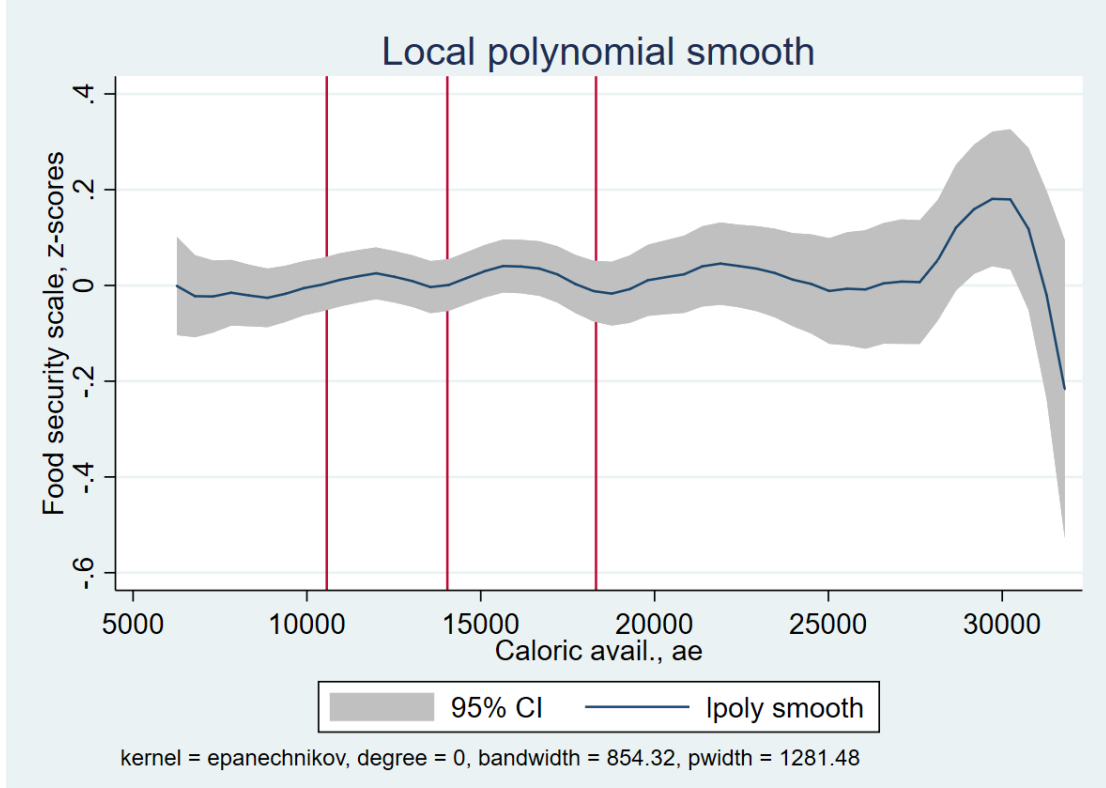

Note: Caloric availability measured with respect to the past 7 days in terms of adults equivalent. 
Figure 3: Correlation between scale scores and food security measures. Malawi panel, controlling for household and year fixed-effects.

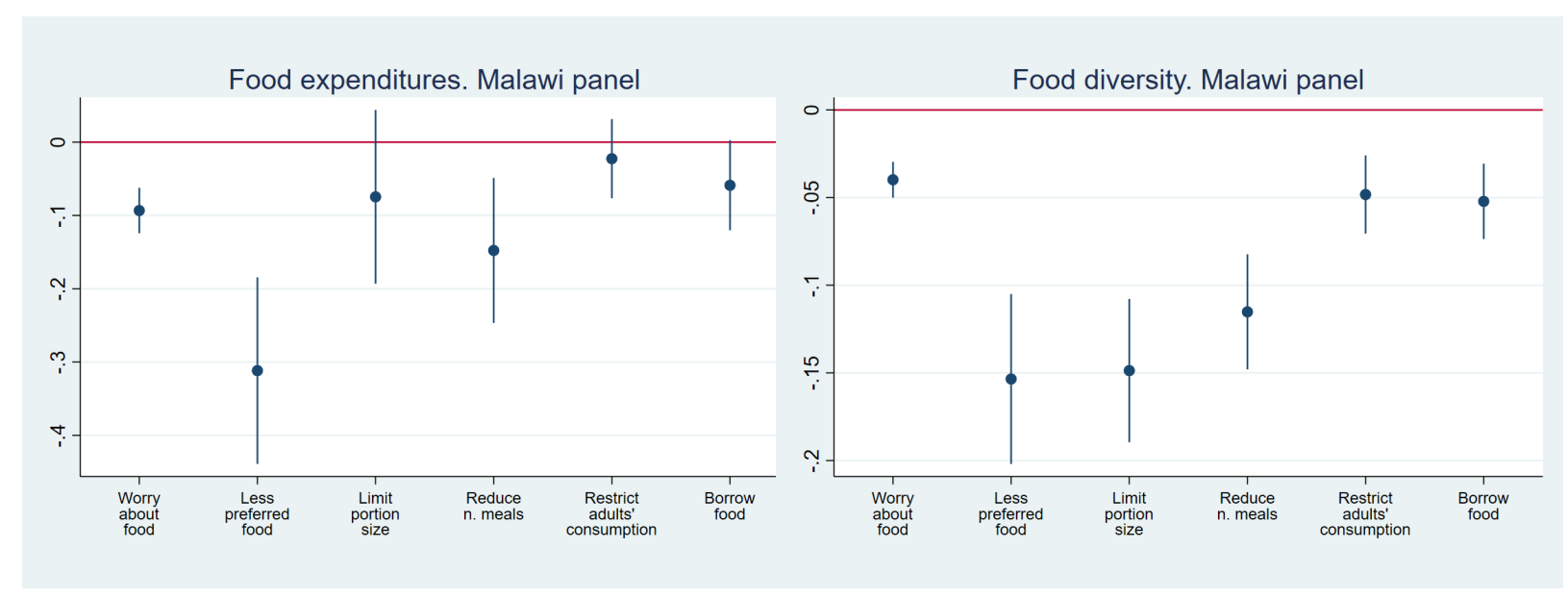

Figure 4: Correlation between scale scores and food security measures. Nigeria panel, controlling for household and year fixed-effects.

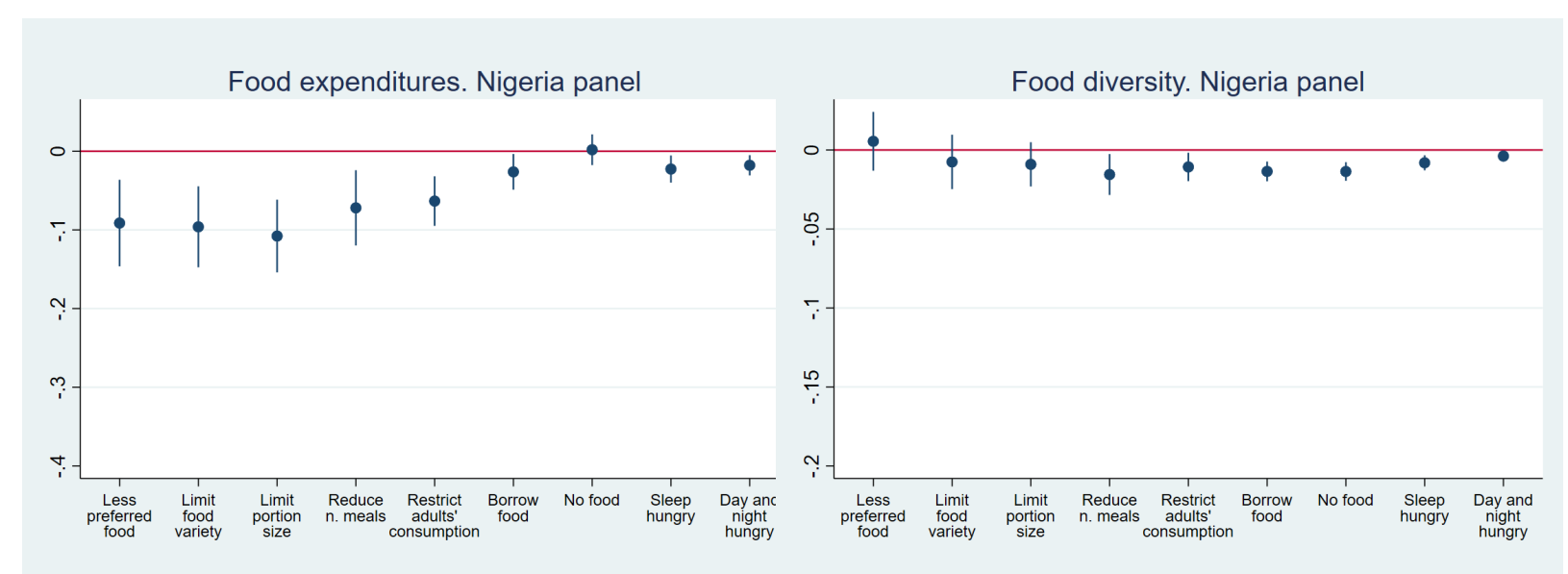


Figure 5: Correlation between scale scores and food security measures. Tanzania panel, controlling for household and year fixed-effects.
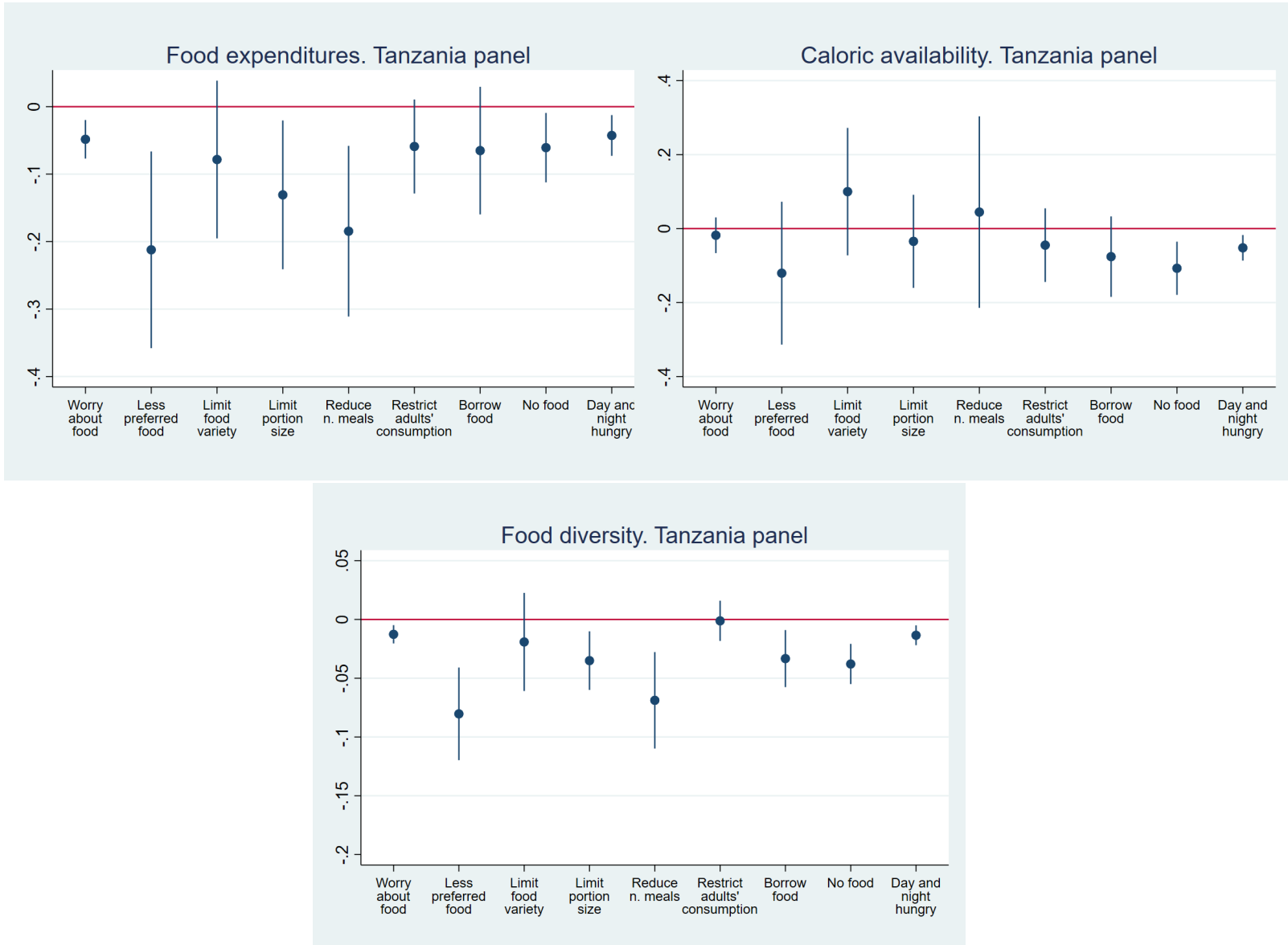

Figure 6: Consumption Adequacy Question and scale items.

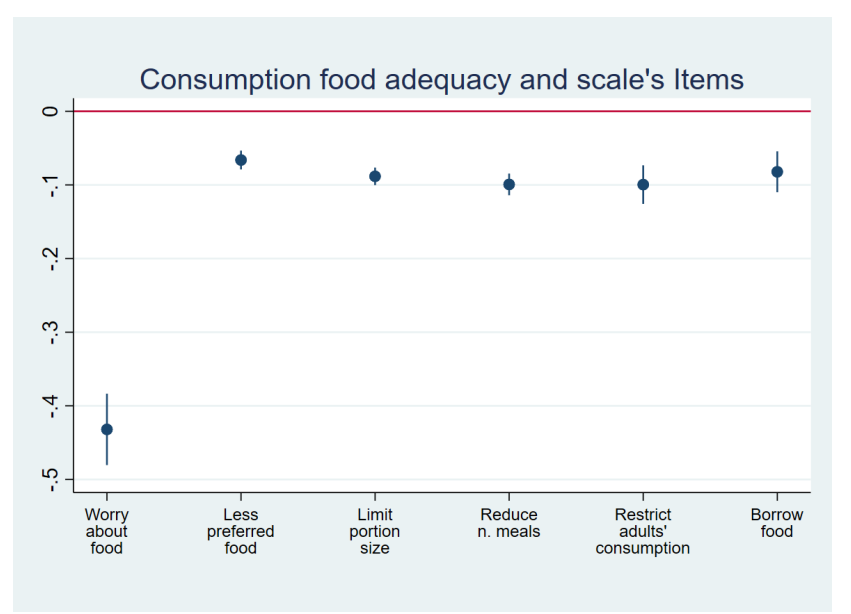




\section{Tables}

Table 1: Food security scale item descriptive statistics. Average over the two data rounds.

\begin{tabular}{|c|c|c|}
\hline Malawi & Nigeria & Tanzania \\
\hline $\begin{array}{l}\text { 1. In the past } 7 \text { days did } \\
\text { you worry that your house- } \\
\text { hold would not have enough } \\
\text { food? }\end{array}$ & & $\begin{array}{l}\text { 1. In the past } 7 \text { days did } \\
\text { you worry that your house- } \\
\text { hold would not have enough } \\
\text { food? }\end{array}$ \\
\hline \multicolumn{3}{|c|}{ In the past seven days, how many days you or someone in your household had to: } \\
\hline \multirow{2}{*}{ 2. Rely on less preferred food? } & 1. Rely on less preferred food? & 2. Rely on less preferred food? \\
\hline & $\begin{array}{l}\text { 2. Limit the variety of food } \\
\text { eaten? }\end{array}$ & $\begin{array}{l}\text { 3. Limit the variety of food } \\
\text { eaten? }\end{array}$ \\
\hline $\begin{array}{l}\text { 3. Limit the portion size at } \\
\text { meal-times? }\end{array}$ & $\begin{array}{l}\text { 3. Limit the portion size at } \\
\text { meal-times? }\end{array}$ & $\begin{array}{l}\text { 4. Limit the portion size at } \\
\text { meal-times? }\end{array}$ \\
\hline $\begin{array}{l}\text { 4. Reduce number of meals } \\
\text { eaten in a day? }\end{array}$ & $\begin{array}{l}\text { 4. Reduce number of meals } \\
\text { eaten in a day? }\end{array}$ & $\begin{array}{l}\text { 5. Reduce number of meals } \\
\text { eaten in a day? }\end{array}$ \\
\hline $\begin{array}{l}\text { 5. Restrict consumption by } \\
\text { adults in order for small chil- } \\
\text { dren to eat? }\end{array}$ & $\begin{array}{l}\text { 5. Restrict consumption by } \\
\text { adults in order for small chil- } \\
\text { dren to eat? }\end{array}$ & $\begin{array}{l}\text { 6. Restrict consumption by } \\
\text { adults in order for small chil- } \\
\text { dren to eat? }\end{array}$ \\
\hline \multirow{4}{*}{$\begin{array}{l}\text { 6. Borrow food, or rely on } \\
\text { help from a friend or relative? }\end{array}$} & $\begin{array}{l}\text { 6. Borrow food, or rely on } \\
\text { help from a friend or relative? }\end{array}$ & $\begin{array}{l}\text { 7. Borrow food, or rely on } \\
\text { help from a friend or relative? }\end{array}$ \\
\hline & 7. Have no food of any kind? & 8. Have no food of any kind? \\
\hline & $\begin{array}{l}\text { 8. Go at sleep hungry because } \\
\text { there is not enough food? }\end{array}$ & \\
\hline & $\begin{array}{l}\text { 9. Go a whole day and night } \\
\text { without eating? }\end{array}$ & $\begin{array}{l}\text { 9. Go a whole day and night } \\
\text { without eating? }\end{array}$ \\
\hline
\end{tabular}


Table 2: Descriptive statistics of food insecurity measures across countries. Average over the two data rounds.

\begin{tabular}{lccc}
\hline \hline & & & \\
& Malawi & Nigeria & Tanzania \\
\hline \multirow{3}{*}{ Scale score } & & & \\
& -3.13 & -3.36 & -3.74 \\
Food diversity & $(4.93)$ & $(5.84)$ & $(6.47)$ \\
& 0.00 & 0.00 & 0.00 \\
Food exp., ae & $(1.85$ & 7.16 & 7.86 \\
& 9.00 & $(1.98)$ & $(2.25)$ \\
Caloric availability, ae & 8.17 & 11.37 & 8.00 \\
& $(7.54)$ & $(9.85)$ & $(6.16)$ \\
Share of poor HHs & 6.04 & 9.09 & 6.58 \\
& $(7677.25)$ & $(13383.24)$ & $(8324.96)$ \\
N. children U5 & 0.471 .70 & 7177.45 & 14040.09 \\
& $(0.50)$ & 0.33 & 0.48 \\
Assets' value (log) & 0.00 & $0.47)$ & $(0.50)$ \\
& 0.98 & 1.03 & 0.00 \\
& $(0.94)$ & $(1.24)$ & $(0.65)$ \\
& 1.00 & 1.00 & 0.00 \\
Observations & 9.51 & 11.22 & 14.63 \\
\hline \hline
\end{tabular}

Sample mean and median, standard deviations in parentheses. Scale scores are inverted and not standardised. The share of poor households is defined by the share of households with per capita expenditures under $1.25 \$$ per day. 
Table 3: Descriptive statistics for food security scale items. Average over the two data rounds.

\begin{tabular}{|c|c|c|c|}
\hline & Malawi & Nigeria & Tanzania \\
\hline Worry about food & $\begin{array}{l}-0.313 \\
(0.464)\end{array}$ & & $\begin{array}{c}-0.322 \\
(0.467)\end{array}$ \\
\hline Less preferred food & $\begin{array}{l}-1.029 \\
(1.811)\end{array}$ & $\begin{array}{c}-0.995 \\
(1.671)\end{array}$ & $\begin{array}{c}-0.969 \\
(1.895)\end{array}$ \\
\hline Limit food variety & & $\begin{array}{c}-0.814 \\
(1.484)\end{array}$ & $\begin{array}{c}-0.552 \\
(1.525)\end{array}$ \\
\hline Limit portion size & $\begin{array}{c}-0.739 \\
(1.573)\end{array}$ & $\begin{array}{c}-0.558 \\
(1.240)\end{array}$ & $\begin{array}{c}-0.421 \\
(1.275)\end{array}$ \\
\hline Reduce number of meals & $\begin{array}{c}-0.540 \\
(1.338)\end{array}$ & $\begin{array}{c}-0.484 \\
(1.171)\end{array}$ & $\begin{array}{c}-0.817 \\
(1.903)\end{array}$ \\
\hline Restrict adult consumption & $\begin{array}{c}-0.222 \\
(0.781)\end{array}$ & $\begin{array}{c}-0.244 \\
(0.855)\end{array}$ & $\begin{array}{c}-0.183 \\
(0.875)\end{array}$ \\
\hline Borrow food & $\begin{array}{c}-0.289 \\
(0.850)\end{array}$ & $\begin{array}{c}-0.0975 \\
(0.520)\end{array}$ & $\begin{array}{c}-0.261 \\
(0.992)\end{array}$ \\
\hline Have no food & & $\begin{array}{c}-0.0862 \\
(0.455)\end{array}$ & $\begin{array}{c}-0.156 \\
(0.739)\end{array}$ \\
\hline Hungry at night & & $\begin{array}{c}-0.0662 \\
(0.369)\end{array}$ & \\
\hline Day and night without eating & & $\begin{array}{r}-0.0295 \\
(0.261)\end{array}$ & $\begin{array}{c}-0.0539 \\
(0.345)\end{array}$ \\
\hline Observations & 5420 & 9177 & 7240 \\
\hline
\end{tabular}

Sample mean and standard deviations. 
Table 4: Relation between food security scale scores, expenditures and food diversity. Malawi, Nigeria and Tanzania cross-section samples in 2011 and 2013.

Dep. var.: Food security scale, z-scores
(1)
$(2)$
$(3)$
(4)
$(5)$
(6)

\section{Panel A. Malawi}

Food exp. log, ae

$$
\begin{array}{cc}
0.2544^{* * *} & 0.4601^{* * *} \\
(0.03) & (0.03)
\end{array}
$$

Food diversity

$$
0.1399^{* * *} \quad 0.1651^{* * *}
$$

\begin{tabular}{lcccc} 
& & & $(0.01)$ & $(0.01)$ \\
Data round & First & Second & First & Second \\
$\mathrm{N}$ & 2583 & 2589 & 2710 & 2710 \\
adj- $\mathrm{R}^{2}$ & .029 & .078 & .065 & .087 \\
\hline
\end{tabular}

\section{Panel B. Nigeria}

$\begin{array}{lcc}\text { Food exp. log, ae } & 0.0941^{* *} & 0.2793^{* * *} \\ \text { Food diversity } & (0.04) & (0.04)\end{array}$

Food diversity

$$
\begin{array}{cc}
-0.0238^{* * *} & -0.0345^{* * *} \\
(0.01) & (0.01)
\end{array}
$$

\begin{tabular}{lcccc} 
Data round & First & Second & First & Second \\
$\mathrm{N}$ & 3949 & 3933 & 4539 & 4603 \\
adj- $\mathrm{R}^{2}$ & 0.0023 & .023 & 0.0019 & 0.0045 \\
\hline
\end{tabular}

\section{Panel C. Tanzania}

Food exp. log, ae

$$
\begin{array}{cc}
0.2910^{* * *} & 0.2399^{* * *} \\
(0.03) & (0.03)
\end{array}
$$

Food diversity

$$
\begin{array}{cc}
0.0817^{* * *} & 0.0652^{* * *} \\
(0.01) & (0.01)
\end{array}
$$

Caloric avail. $\log$, ae

$$
\begin{array}{ll}
0.0390 & 0.0280 \\
(0.05) & (0.05)
\end{array}
$$

\begin{tabular}{lcccccc} 
Data round & First & Second & First & Second & First & Second \\
$\mathrm{N}$ & 3482 & 3483 & 3619 & 3621 & 2812 & 2765 \\
adj- $^{2}$ & .032 & .023 & .029 & .024 & -0.00015 & -0.0002 .4 \\
\hline
\end{tabular}

Robust standard errors clustered at the enumeration area. Food expenditures in real terms converted to 2011 US dollars are in logarithmic form. Caloric availability is in logarithmic form as well. 
Table 5: Relation between food security scale scores, expenditures and food diversity. Pooled samples.

Dep. var.: Food security scale, z-scores

(1)

$(2)$

$(3)$

\section{Panel A. Malawi}

Food exp. log, ae $\quad 0.3100^{* * *}$

$(0.04)$

Food diversity

$0.1040^{* * *}$

\begin{tabular}{lcc} 
& & $(0.01)$ \\
$\mathrm{N}$ & 4470 & 4541 \\
adj-R & .038 & .045 \\
\hline
\end{tabular}

\section{Panel B. Nigeria}

Food exp. log, ae $\quad 0.155^{* * *}$

$(0.02)$

Food diversity

$-0.040^{* * *}$

15554

$\begin{array}{lll}\operatorname{adj}-R^{2} & .012 & .012\end{array}$

\section{Panel C. Tanzania}

Food exp. log, ae $\quad 0.2515^{* * *}$

Food diversity $0.1127^{* * *}$

Caloric avail. $\log$, ae $-0.0261$

$\begin{array}{llll}\mathrm{N} & 6700 & 6746 & 5506\end{array}$

\begin{tabular}{llll} 
adj-R $R^{2}$ & .038 & .059 & .025 \\
\hline \hline
\end{tabular}

All regressions control for household time-varying characteristics and round fixed effects. Robust standard errors clustered at the enumeration area. Food expenditures in real terms converted to 2011 US dollars are in logarithmic form. Caloric availability is in logarithmic form as well. 
Table 6: Relation between food security scale scores, expenditures and food diversity. Household fixed effects. Malawi, Nigeria and Tanzania panel data.

\begin{tabular}{lcc}
\hline \hline \multicolumn{3}{c}{ Dep. var.: Food security scale, z-scores } \\
\multicolumn{4}{c}{$(1)$} & $(2)$ & $(3)$ \\
\hline Panel A. Malawi & & \\
Food exp. log, ae & $0.1596^{* * *}$ \\
& $(0.05)$ & \\
Food diversity & & $0.0890^{* * *}$ \\
& & $(0.02)$ \\
$\mathrm{N}$ & 4470 & 4541 \\
adj- $\mathrm{R}^{2}$ & 0.0063 & .017 \\
\hline
\end{tabular}

\section{Panel B. Nigeria}

Food exp. log, ae $\quad 0.097^{* * *}$

Food diversity $\quad 0.010$

\begin{tabular}{lcc} 
& & $(0.01)$ \\
$\mathrm{N}$ & 15554 & 17351 \\
adj- $\mathrm{R}^{2}$ & 0.0023 & 0.00051 \\
\hline
\end{tabular}

Panel C. Tanzania

Food exp. log, ae $\quad 0.1838^{* * *}$

Food diversity $0.0408^{* * *}$

Caloric avail. $\log$, ae

\begin{tabular}{lccc}
$\mathrm{N}$ & 6700 & 6746 & 5506 \\
adj-R $^{2}$ & 0.0068 & 0.0051 & 0.0022 \\
\hline
\end{tabular}

All regressions control for household fixed effects, data round fixed effects and time-varying household characteristics (n. young children, value of assets, dummy for monetary poverty). Robust standard errors clustered at the enumeration area. Food expenditures expressed in real terms converted to 2011 US dollars in logarithmic form. Caloric availability is in logarithmic form as well. 
Table 7: Relation between food security scale scores, expenditures and food diversity for poor and non-poor households. Household fixed effects. Malawi, Nigeria and Tanzania panel data.

\begin{tabular}{|c|c|c|c|c|c|c|}
\hline \multicolumn{7}{|c|}{ Dep. var.: Food security scale, z-scores } \\
\hline & $\begin{array}{c}\text { Poor } \\
(1)\end{array}$ & $\begin{array}{c}\text { Non-poor } \\
(2)\end{array}$ & $\begin{array}{c}\text { Poor } \\
(3)\end{array}$ & $\begin{array}{c}\text { Non-poor } \\
(4)\end{array}$ & $\begin{array}{c}\text { Poor } \\
(5)\end{array}$ & $\begin{array}{c}\text { Non-poor } \\
(6)\end{array}$ \\
\hline \multicolumn{7}{|l|}{ Panel A. Malawi } \\
\hline Food exp. log, ae & $\begin{array}{c}0.1720^{* * *} \\
(0.06)\end{array}$ & $\begin{array}{c}0.1869^{* *} \\
(0.08)\end{array}$ & & & & \\
\hline Food diversity & & & $\begin{array}{c}0.1029^{* * *} \\
(0.02)\end{array}$ & $\begin{array}{c}0.0605^{* *} \\
(0.03)\end{array}$ & & \\
\hline $\mathrm{N}$ & 3203 & 1235 & 3263 & 1264 & & \\
\hline $\operatorname{adj}-R^{2}$ & .009 & .026 & .025 & .024 & & \\
\hline \multicolumn{7}{|l|}{ Panel B. Nigeria } \\
\hline Food exp. log, ae & $\begin{array}{c}0.081^{* *} \\
(0.03)\end{array}$ & $\begin{array}{c}0.120^{* * *} \\
(0.03)\end{array}$ & & & & \\
\hline Food diversity & & & $\begin{array}{l}0.018^{*} \\
(0.01)\end{array}$ & $\begin{array}{l}0.003 \\
(0.01)\end{array}$ & & \\
\hline $\begin{array}{l}\mathrm{N} \\
\text { adj-R }\end{array}$ & $\begin{array}{l}6733 \\
.001\end{array}$ & $\begin{array}{l}8655 \\
.0038\end{array}$ & $\begin{array}{l}7541 \\
.0007\end{array}$ & $\begin{array}{c}9795 \\
0.000002\end{array}$ & & \\
\hline
\end{tabular}

\section{Panel C. Tanzania}

Food exp. log, ae $\quad 0.2721^{* *} \quad 0.0583$

(0.11) (0.07)

Food diversity

$0.0863^{* * *} \quad 0.0157$

$(0.02) \quad(0.02)$

Caloric avail. $\log$, ae

$1069-0.0126$

(0.11) (0.09)

\begin{tabular}{lcccccc}
$\mathrm{N}$ & 3412 & 3288 & 3423 & 3323 & 2865 & 2641 \\
adj- $^{2}$ & .011 & 0.0031 & .013 & 0.003 & 0.0023 & 0.0021 \\
\hline
\end{tabular}

Poor households are defined as living on less than $\$ 1.25$ a day in the first data round. All regressions control for household fixed effects, data round fixed effects and time-varying household characteristics (n. young children, value of assets). Robust standard errors are clustered at the enumeration area. Food expenditures are expressed in real terms converted to 2011 US dollars in logarithmic form. Caloric availability is in logarithmic form as well. 
Table 8: Relation between food security scale scores, expenditures and food diversity, controlling for Consumption Adequacy Question. Malawi panel.

Dep. var.: Food security scale, z-scores

\begin{tabular}{lcc} 
Food exp. log, ae & $\begin{array}{c}0.1166^{* *} \\
(0.05)\end{array}$ & \\
Food diversity & & $0.0611^{* * *}$ \\
& & $(0.02)$ \\
Consumption Adequacy & $0.4505^{* * *}$ & $0.4358^{* * *}$ \\
& $(0.04)$ & $(0.04)$ \\
\hline $\mathrm{N}$ & 4470 & 4541 \\
adj- $\mathrm{R}^{2}$ & .085 & .089 \\
\hline \hline \multicolumn{2}{l}{ All regressions control for household fixed effects and data round } \\
fixed effects. Robust standard errors are clustered at the enumer- \\
ation area. Food expenditures in real terms converted to 2010 US \\
dollars are in logarithmic form.
\end{tabular}

